\title{
ACERCA DE SILVESTRE REVUELTAS
}

Por Jorge Velazco

Es posible que Silvestre Revueltas sea el artista mexicano sobre el cual existen más mitos y cuentos. Su vida corta e intensa, su romanticismo violento y exacerbado, su genio indomable y explosivo, sus tres matrimonios, incluso su alcoholismo, lo han llevado a la categoría de hombreleyenda. Por otra parte, Revueltas ha llegado a ser un valor aceptado, un monumento nacional que tirios y troyanos reconocen sin discutir, si bien nadie (fuera de un pequeño círculo de músicos) sabe a ciencia cierta cuáles son sus méritos, por qué era un gran artista y cuál es la razón por la que debe reconocerse su valor, además de una curiosa situación que ha llevado al público a desconocer la mayor parte de su obra, a pesar de que muchas melodias de Revueltas (aquellas en las que captó el espfritu nacional y la alegre melancolia del mexicano) viven en el ofdo de muchas personas que no las tienen identificadas como creación del popular músico y revolucionario artista.

No cabe duda que los músicos más importantes de la primera mitad del siglo xx en México han sido Carlos Chávez y Silvestre Revueltas. Esta importancia atribuida a estos dos artistas no está ligada a las ideas de omnipotencia o poder político, ni pretende comprometer la trascendencia de otros músicos mexicanos tan valiosos como Manuel $M$. Ponce, sino a la obra que ambos realizaron y a la forma como lograron modificar el medio artístico y profesional, además de su labor como pilares del moderno nacionalismo mexicano, cuya expresión plástica y literaria habfa sido ya expuesta por Azuela, Villaurrutia, Orozco y Rivera. Chávez integró un esquema mexicano de fuerte raíz en las antiguas civilizaciones de Mesoamérica y Revueltas logró sintetizar ese núcleo emocional que se halla escondido debajo de los aspectos pintorescos de lo popular $\mathrm{y}$, al igual que Chávez y tal vez en mayor grado, pudo hallar los intervalos, el ritmo, la armonía y las formas adecuadas para componer música inconfudiblemente mexicana sin acudir a temas folklóricos ni canciones populares, sino escribir siempre música propia y original, que cataliza las inquietudes nacionales y que es mexicana sin ser mexicanista. La posición romántica de Revueltas le permitió aglutinar sus anhelos juveniles y nacionales con su talento y sus formas expresivas.

No existe una biografía completa de Revueltas. Por una parte, estamos todavia muy cerca de su persona en el tiempo y no conseguimos enfo- 
carlo fácilmente con una perspectiva adecuada; además, los testimonios de quienes lo conocieron son válidos pero no han sido sistematizados por investigador alguno, y esos mismos testimonios configuran el anecdotario que rodea la figura del compositor de esa aura legendaria que hace tan confusa su personalidad. Recientemente la Dirección General de Difusión Cultural de la UNAM, en coedición con la Sociedad de Autores y Compositores de Música ha publicado un Epistolario de Revueltas que resulta el primer testimonio directo del músico. Los Apuntes para una semblanza de Silvestre, publicados por el hermano del compositor, José, en 1966, están más cerca de una interpretación literaria, de una relación entre un genio musical y un sensitivo escritor que de una fuente objetiva de información. Imagen de Silvestre Revueltas, de Juan Marinello, editada también en 1966, es tan sólo un anecdotario sistematizado que también ilumina en forma parcial. El libro de Guillermo Contreras, Silvestre Revueltas: genio atormentado, es una obra excesivamente angustiada, que desfigura demasiado la figura del músico enfatizando los aspectos difíciles de la lucha del genio contra la vida y el medio. Como esos panfletos en los que Chopin es pura tuberculosis, Beethoven nada más que sordera, Schubert una miserable vida de pobreza y Mozart un entierro solitario en la fosa común bajo una nevada. La biografía completa del gran músico está aún por escribirse y no parece haber la combinación ideal de capacidad, conocimiento e interés para que alguien la elabore.

Silvestre Revueltas recibió una fuerte influencia de Chávez al principio de su carrera como compositor, pero a partir de la composición de su primera obra sinfónica, Cuauhnáhuac, adquirió su personalidad musical propia. El introspectivo y culto concepto musical de Chávez no se adecuaba al temperamento musical espontáneo y vivaz de Revueltas. El aspecto pintoresco del pueblo mexicano, el jolgorio de mercados, calles y carpas se acerca más a la posición de Revueltas. Ese melancólico humor tan característicamente mexicano, que Samuel Ramos estudió con tanto acierto y que unifica el valor con el masoquismo, parece ser autóctono de la música que creó. La mezcla de estímulos disímiles y repentinos aparece constantemente en su música. Chávez tuvo una importancia excepcional y definitiva en la vida y obra de Revueltas. Así como la actividad de Chávez conformó la música mexicana de 1930 a 1960 y le dio una forma característica, al grado de que si Chávez no hubiera existido, nuestra música seria distinta, asi la vida creadora de Revueltas está condicionada en sus principios por la acción 


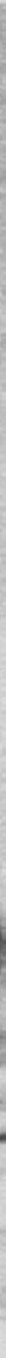

1. Silvestre Revueltas. 
DOI: http://dx.doi.org/10.22201/iie.18703062e.1976.45.1041

$$
\text { r. }
$$


de Carlos Chávez. Fue éste quien alentó a Revueltas para que se volviera un compositor, quien le enseñó a pensar metólicamente en la composición y le dio armas y oportunidades profesionales que Revueltas no habia tenido antes. El que posteriormente chocara el espiritu libre $e$ informal de Revueltas con el autoritarismo y férrea discipl na de Chávez y apareciera una brecha entre los dos no puede invalidar las palabras del propio Revueltas: "Cuauhnáhuac, Colorines, Janitzio, etcétera, jamás hubieran visto la luz sin el estímulo y la alentadora energía de Carlos Chávez."

El lenguaje de Revueltas, formal y armónico, aparece luego de su conocimiento de Stravinski, Falla y Varèse, pero su constante amor por su país lo llevó a una técnica de evocación constante y de respeto y devoción por las cosas triviales de la vida diaria mexicana.

La facilidad, fluidez y espontaneidad de su invención melódica y la colorida y brillante orquestación de sus obras son tal vez las características más inmediatamente perceptibles de su producción. Las partes tienen una vicalidad individual extraordinaria pero contribuyen siempre a la superposición de diversos planos armónicos. Este peculiar enfoque de la politonalidad fue manejado por Revueltas con singular maestría, ya que las voces construyen su plano armónico indiviclual girando siempre en torno a centros tonales muy bien definidos y diferenciados, los cuales tienen relaciones muy claras entre si. Esto lleva a una construcción armónica muy típica de Revueltas, en la que hallamos acordes producidos por la conjunción de diversos momentos armónicos individuales, que tienen un movimiento autónomo cada uno y que sólo se relacionan (desde un punto de vista tonal) con las partes independientes que condicionan el curso de cada plano armónico, coexistiendo solamente con los demás planos para producir el resultado armónico total.

Su conocimiento, tal vez intuitivo, de los recursos orquestales y de las combinaciones instrumentales, era enorme y le permitió lograr muchos mosaicos instrumentales, casi siempre basados en el sabio uso del grupo de percusiones y girando alrededor de los alientos. Resulta curioso que Revueltas, violinista de origen, haya evitado la instrumentación basada en la primacía virtuosística de la cuerda y haya instrumentado utilizando básicamente la bipolaridad de alientos y percusiones. Siempre procuraba establecer fondos sonoros permanentes, de movimiento muy contrastado y activo, sobre los que proyecta sus temas y desarrollos melódicos, usando a veces un doble contrapunto con inclinación a emplear curvas melódicas de gran amplitud. Una cierta influencia afro- 
DOI: http://dx.doi.org/10.22201/iie.18703062e.1976.45.1041 
DOI: http://dx.doi.org/10.22201/iie.18703062e.1976.45.1041 
rovski en composición y Sametini en violín. Volvió a México donde se dedicó a dar conciertos durante dos años. Una febril actividad marca este periodo, ya había tratado de organizar una orquesta sinfónica en los EEUU, pero fracasó al chocar contra los intereses creados de los viejos maestros. Regresó a estudiar en Chicago en 1922 y tomó clases con Vaclav Kochanski y Ottokar Sevcik. Se graduó en 1924 y ese mismo año principió a dar recitales con Carlos Chávez al piano, en los que tocó por primera vez en México las obras de la más avanzada vanguardia europea y americana del momento. Viajó de nuevo a los EE. UU. en 1926 tratando de hacer una carrera comercial, vivió en San Antonio, Texas y Mobile, Alabama, como violinista en orquestas de teatro y director de orquesta. El medio no le fue tan propicio como él esperaba y se repatrió en 1928. Al año siguiente, en 1929, Chávez lo nombró subdirector de la Orquesta Sinfónica de México y alentado por el mismo Chávez, volvió a componer tras de haber asistido a unos cursillos impartidos por el director y formador de la orquesta. Pero Revueltas no tenía dinero y pronto la fuerte presión económica bajo la que vivía le obligó a buscar más trabajo, más ingresos y a fatigarse en exceso. En 1934, principió a dar cursos de música de cámara en el Conservatorio, dirigía la orquesta estudiantil del plantel y compuso música para películas, pues no le pagaban mal por hacerlo y necesitaba desesperadamente todo ingreso posible. De suyo, mucho de su energía creadora se gastó en la composición de música para el cine.

No estả claro en qué época y por qué causas principió a beber, si bien las dificultades provocadas por el choque de su infinita sensibilidad con el crudo medio social puede haber sido un factor contribuyente. Pero el alcoholismo de Revueltas, que añade un toque trágico a su vida, fue rápidamente reconocido en el medio musical, primero como rumor y luego como lamentable realidad. Su genio productor le salvó del ostracismo social y le rodeó de una especie de compasión o de censura según la simpatía, antipatía o envidia de quienes consideraban el problema. Es indudable que el alcoholismo fue importantísimo factor en la temprana desaparición del músico, pero aún hay sentimientos familiares que se lastiman por el asunto y su investigación resulta molesta, difícil y enojosa. Tan sólo será preciso tomarlo en cuenta como otro elemento de presión que, junto con los problemas económicos y profesionales, atormentaban a Revueltas. La Liga de Escritores y Artistas Revolucionarios (LEAR), cuya secretaria ocupó durante algún tiempo, fue una clara expresión de su conciencia política y de sus ideas 
sociales. Revueltas fue un artista comprometido con la causa socialista, si bien jamás cometió el error de trasladar a su arte sus pensamientos polítícos ni mezcló la música con sus actitudes militantes. Ningún creador inteligente y equilibrado como compositor es capaz de mediatizar su obra en favor de una posición politica. Entre 1937 y 1938 fue a España, en parte para mostrar su devoción por la causa de la República y se presentó como director de orquesta en Madrid, Valencia y Barcelona. El 5 de octubre de 1940, tras de una notable precipitación de su alcoholismo a su regreso de España, murió Revueltas, un poco antes de que se estrenara en Bellas Artes su ballet El Renacuajo Paseador, al parecer víctima de una pulmonía. El ballet La Coronela, cuya composición estaba en proceso en esa época, fue terminado por Blas Galindo y orquestado por Candelario Huízar, músicos afines al modo de ser de Revueltas y amigos personales del gran compositor.

¿Qué tan importante es el alcoholismo de Revueltas en su obra? Desde luego, es un factor de peso en su vida y en el desarrollo de su personalidad $y$, en tal sentido, tuvo influencia sobre su obra creadora. Pero no es posible proceder a la interpretación clínica de un problema estético y poner en primer plano sus problemas personales como justificación o explicación de su obra o de su genio. La sordera de Beethoven, la ceguera de Bach, la tuberculosis de Mozart, la sifilis de Schubert, la locura de Schumann o Wolff, el alcoholismo de Musorgski, la homosexualidad de Chaikorski, la tara neurológica de Smetana o cualquiera de los muchos problemas físicos, mentales o emocionales de los grandes genios no puede ser tomada como medida a motor de sus obras, lo único importante es la música que salió de su pensamiento, como hecho objetivo e inconstetable, para bien o para mal.

El que en un lapso de sólo diez años Revueltas haya producido toda su obra y que ésa sea una obra genial que le ganó un puesto en la música del siglo $\mathrm{xx}$, no sólo en México sino en el resto de América y Europa, es un caso excepcional y constituye un testimonio de la tremenda fuerza creadora del artista. En esos diez años terminó treinta obras, un promedio de tres al año, que se alternaron en su labor con recitales, conciertos, clases, periodismo, dirección de orquesta, actividades políticas y vida personal. Tal exuberancia y riqueza son poco usuales, sobre todo si se tiene en cuenta que dieciséis de esas obras fueron compuestas para gran orquesta y que por lo menos dieciocho de ellas son de importante trascendencia en la música nacional y tal vez algunas no tengan rival en el mundo. 
DOI: http://dx.doi.org/10.22201/iie.18703062e.1976.45.1041 
DOI: http://dx.doi.org/10.22201/iie.18703062e.1976.45.1041 


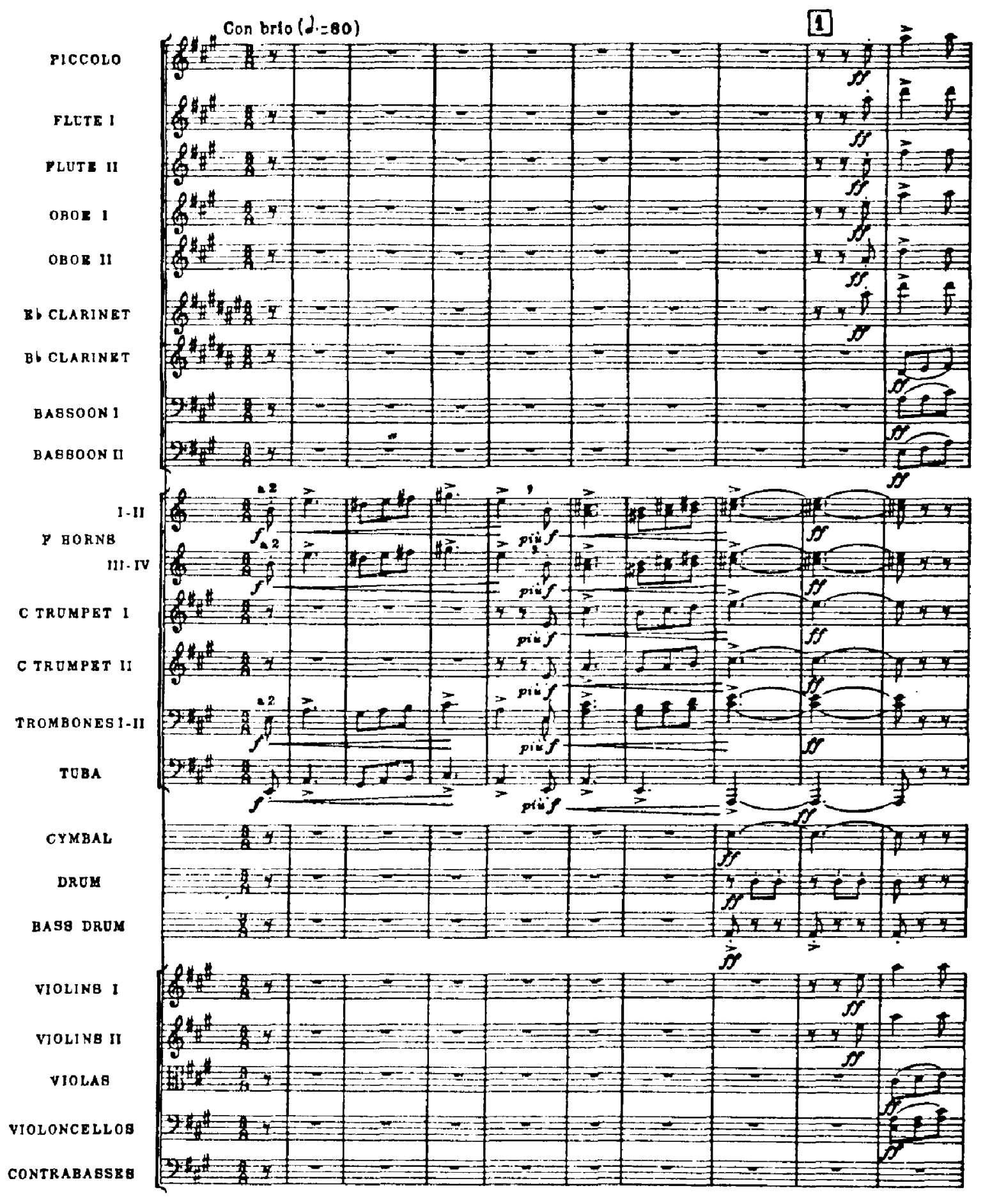

$951-40$

(C) Copyright 1966 by SOUTHERN MUSIC PUBLISHING Co. INC.

International Copyripht Secured

All Riphto Reserred Includink the Right of Public Performance for Profit

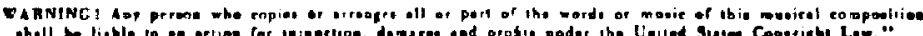


es de piccolo, flauta, clarinete requinto, dos trompetas, trombín, tuba, tam-tam, xilófono, piano, dos violines y contrabajo. Tiene tres números (Baile, Duclo y Son) y la forma es, otra vez, muy característica de Revueltas.

Si bien no se puede afirmar que el Baile tenga las clásicas tres secciones, hay una actitud tripartita, pues la breve introducción a cargo de la trompeta y el piano, lenta y melancólica (quasi recitativo) contrasta con el vivaz allegro que mantiene un ritmo constante. La breve coda final, anuncia, en tempo y carácter, el Duelo, que sí tiene tres secciones claramente determinadas. La central es contrastante de las otras dos y obtiene su apogeo a través de las disonancias que provocan una textura triste, de timbre nostálgico y resignado. La forma como resuelve su enfoque politonal en un acorde de La menor es simplemente magistral.

El Son también está hecho siguiendo la forma A, B, C, y, en contraste con las dos piezas anteriores, emplea constantes cambios rítmicos y tímbricos. Aparecen aquí las terceras paralelas que habia utilizado antes y que nos recuerdan, a veces, una música estilizada del mariachi, máxime por el uso de violines y trompetas como instrumentos melódicos, combinación bastante típica. Las texturas producidas por lás asociaciones de timbres contrastantes (tuba y piccolo, clarinete y piccolo), el uso de la trompeta con piano y con sordina, añaden un toque clásicamente propio de Revueltas.

Janitzio es la única obra que hace una referencia concreta a un elemento mexicano determinado. El constante esquema A, B, C, es tan claro que casi es superfluo reseñarlo. La sección A principia con la cxposición del tema principal, abierta y descarada, gritada a la vez por cornos, trombones y tuba, en tres octavas (Fig. 2).

El tema es cuadrado, con principio anacrúsico y los últimos dos compases admiten dos golpes en los tiempos débiles del compás (3/8) a cargo del tambor, mientras el bombo enfatiza el tiempo fuerte. Este con brio termina con una coda de seis compases, en la que un corno toca el primer motivo del tema y el tambor marca su figura rítmica peculiar (Fig. 3).

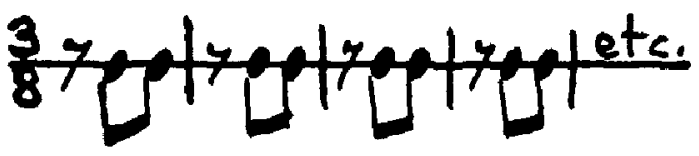

Figura 3

para enlazar con el Lento espressivo de la sección B, cuyo meditativo tema 
DOI: http://dx.doi.org/10.22201/iie.18703062e.1976.45.1041 
DOI: http://dx.doi.org/10.22201/iie.18703062e.1976.45.1041 


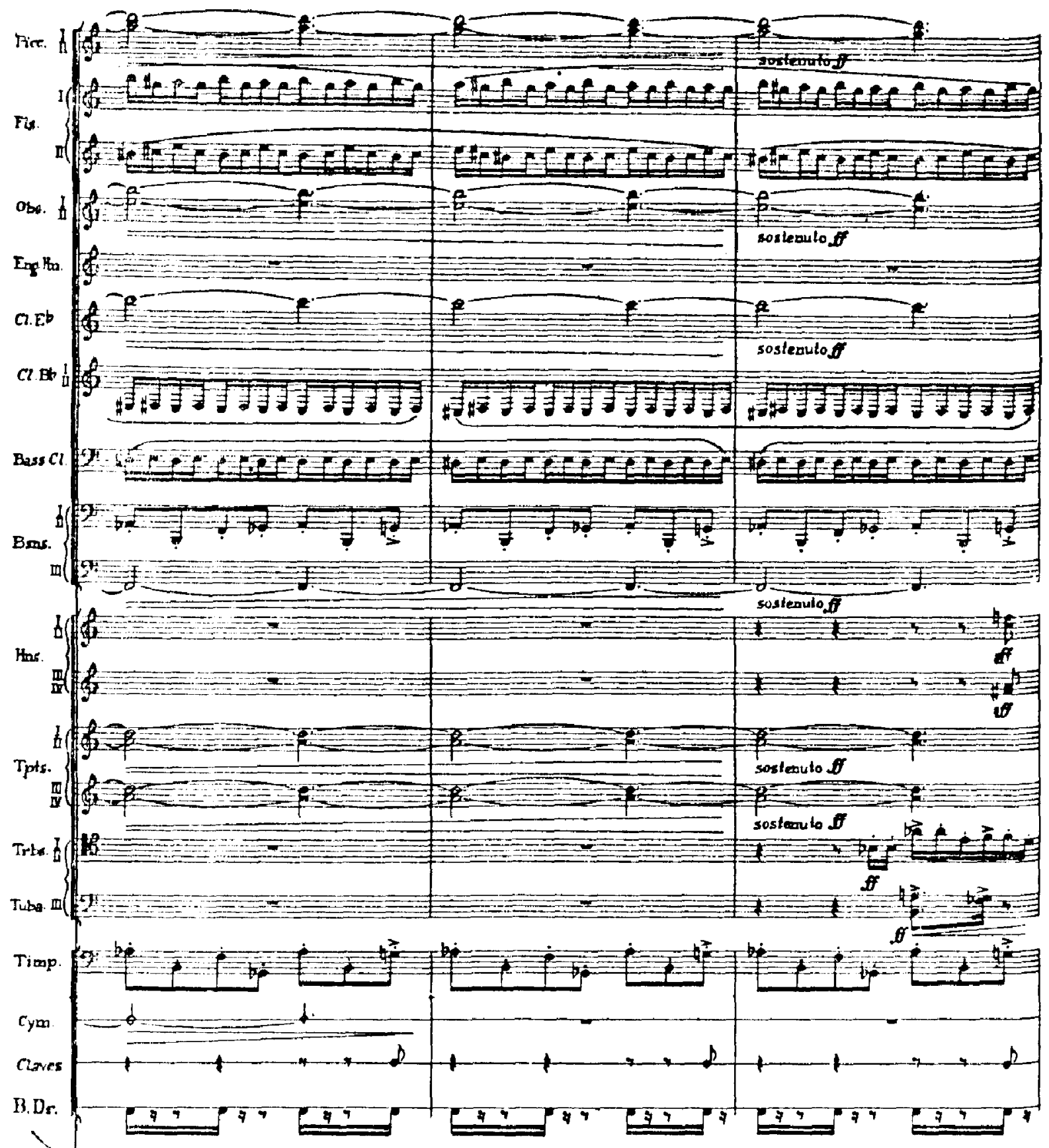

$\checkmark$

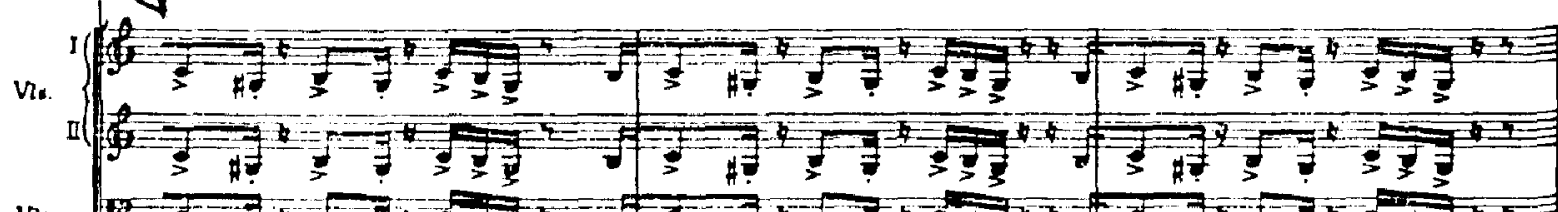

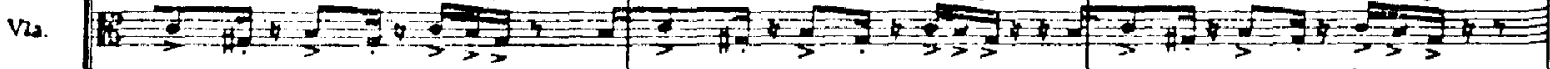

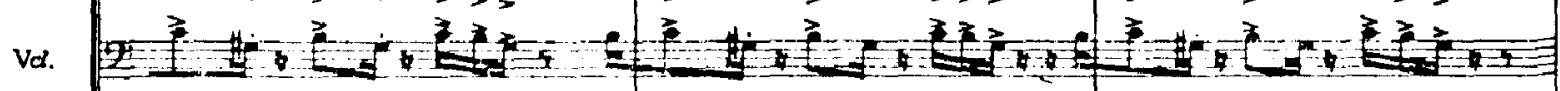

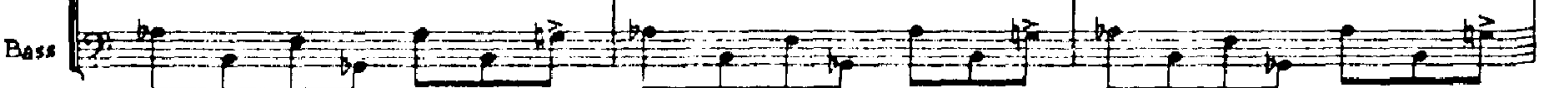


es expuesto primero por el clarinete sobre un pedal de contrabajo y un contrapunto de fagot y luego junto a un corno con trompeta (Fig. 4).

Esta sección es breve y la sección $\mathrm{C}$ presenta 28 compases de tejido conjuntivo antes de gritar el tema principal, por metales, alientos y violines, que se desarrolla alternando con el ostinato de la cuerda hasta el final de la obra. Es digno de llamar la atención el hecho de que el tema principal, de marcadísimo sabor mexicano, es absolutamente original de Revueltas, a pesar de que haya musicólogos capaces de jurar que es una cita de una canción popular.

La obra considerada por muchos como la pieza maestra de Revueltas, Sensemayá, tiene dos versiones. Una para pequeña orquesta, compuesta en 1937 y otra realizada a su regreso de España, en 1938, para una enorme orquesta con 32 instrumentos distintos y una dotación ideal de 93 ejecutantes. Su popularidad, dentro y fuera de México, es exíraordinaria y es una obra sólida, de muy acabada factura y de seguro éxito. Fue inspirada por un poema del poeta cubano Nicolás Guillén, que trata de la muerte ritual de una serpiente y tiene profundo significado mágico.

La obra tiene elementos polirrítmicos y el poema, de esencia onomatopéyica, tiene un gran arrastre ritmico, las palabras Mayombe-bombemayombé se repiten constantemente y Revueltas expuso este motivo rítmico de ocho sílabas en un contexto de siete tiempos de compás combinando el tiempo de su aparición en diversas ocasiones (Figs. $5 a$ y $5 b)$.

EI héroe de la obra es el ritmo, sin embargo, la brillantísima instrumentación merece mención especial. A pesar de que hay quien encuentra una influencia de La Consagración de la Primavera de Stravinski en esta obra, la estética y la posición de construir un clímax basado en la incorporación sucesiva de instrumentos han hecho a otros recordar a Ravel y su técnica del Bolero. El carácter de la música y los recursos rítmicos y el modo como aplica alternadamente matices forte y piano, así como las sucesivas presentaciones de tensión y distensión que culminan con un incréble clímax, en una conjunción donde se mezclan todos los elementos rítmicos y melódicos, permiten afirmar la originalidad y genialidad de la obra. El ritmo fundamental, que aparece al principio en el fagot, al que luego se añade el contrabajo, coexiste con otra figura, ostinato constante, expuso por los tom-toms y el bombo (Fig. 6) . 
DOI: http://dx.doi.org/10.22201/iie.18703062e.1976.45.1041 
DOI: http://dx.doi.org/10.22201/iie.18703062e.1976.45.1041 
32

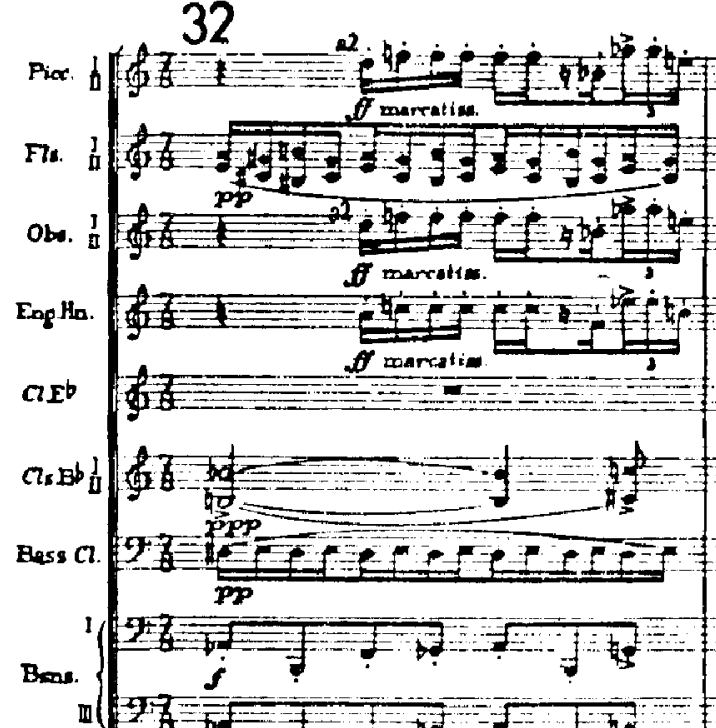

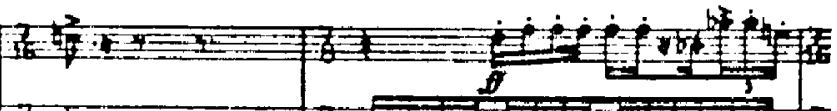
$=$ 7.

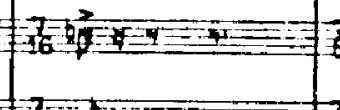

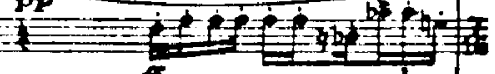

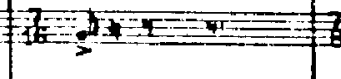

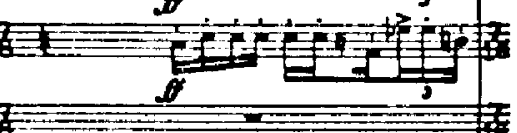
对

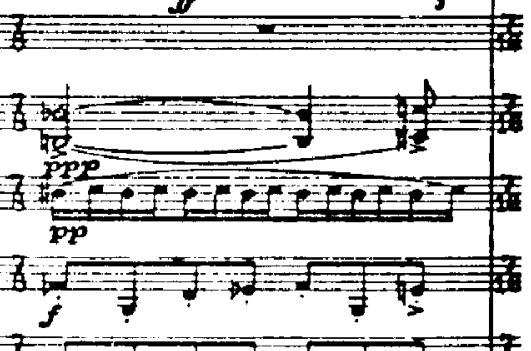
$71=$ $=3$ (a)

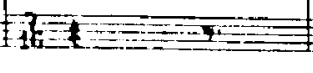
蛊

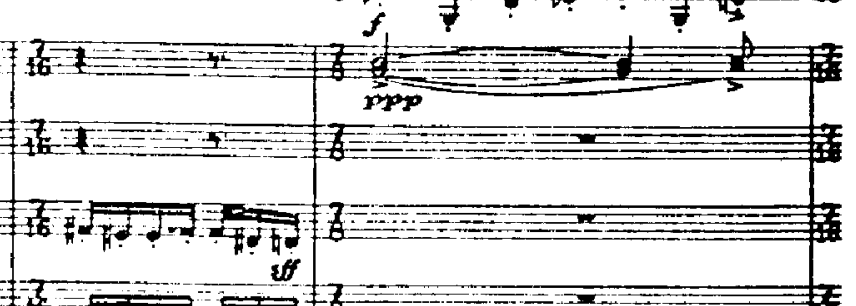
In

Trbs. 9

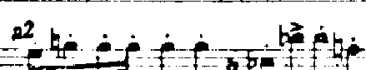

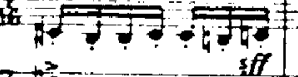

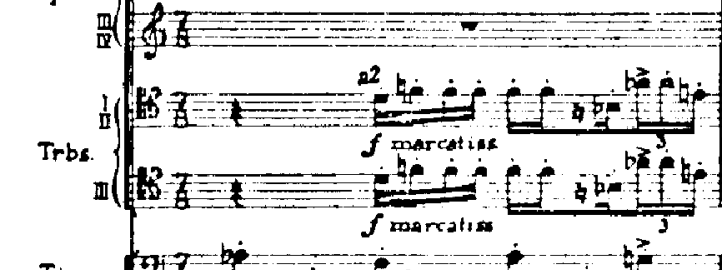
If

$F==d+1$ (7)
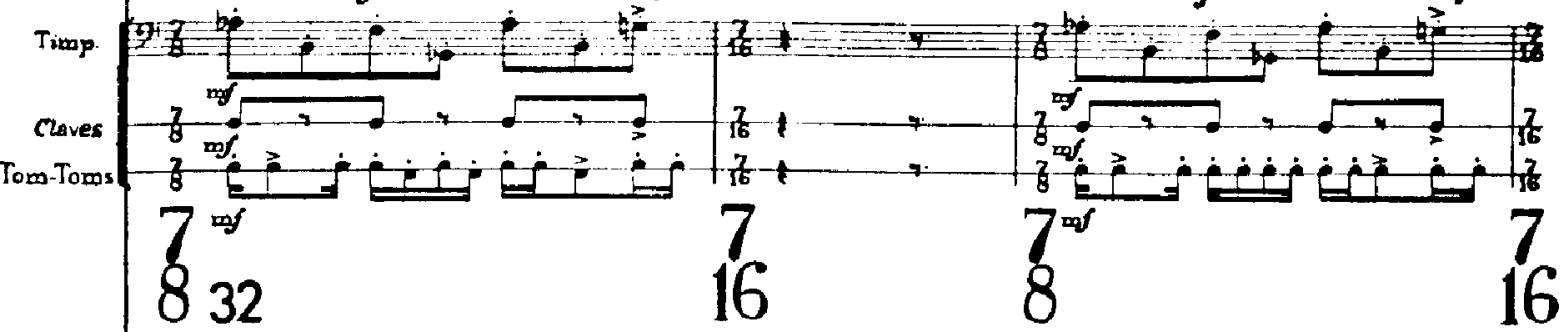

$\mathbf{P}_{i @ 0}$

(4t)

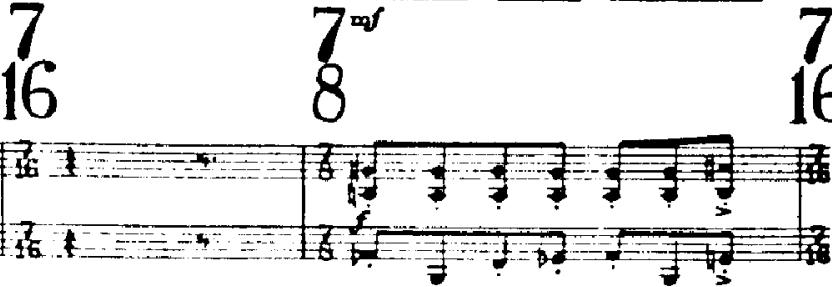

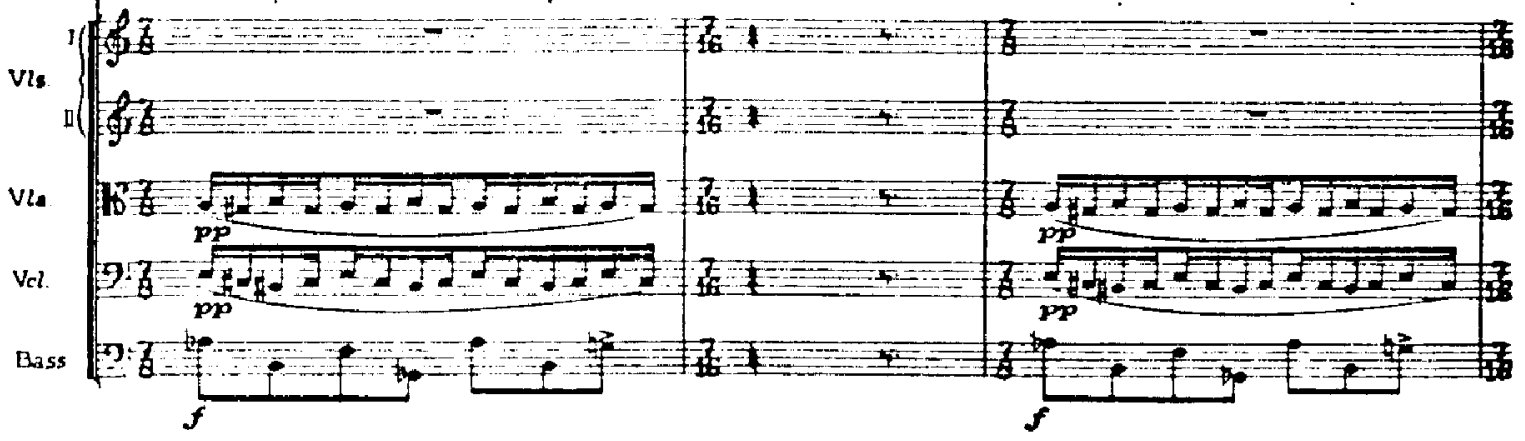




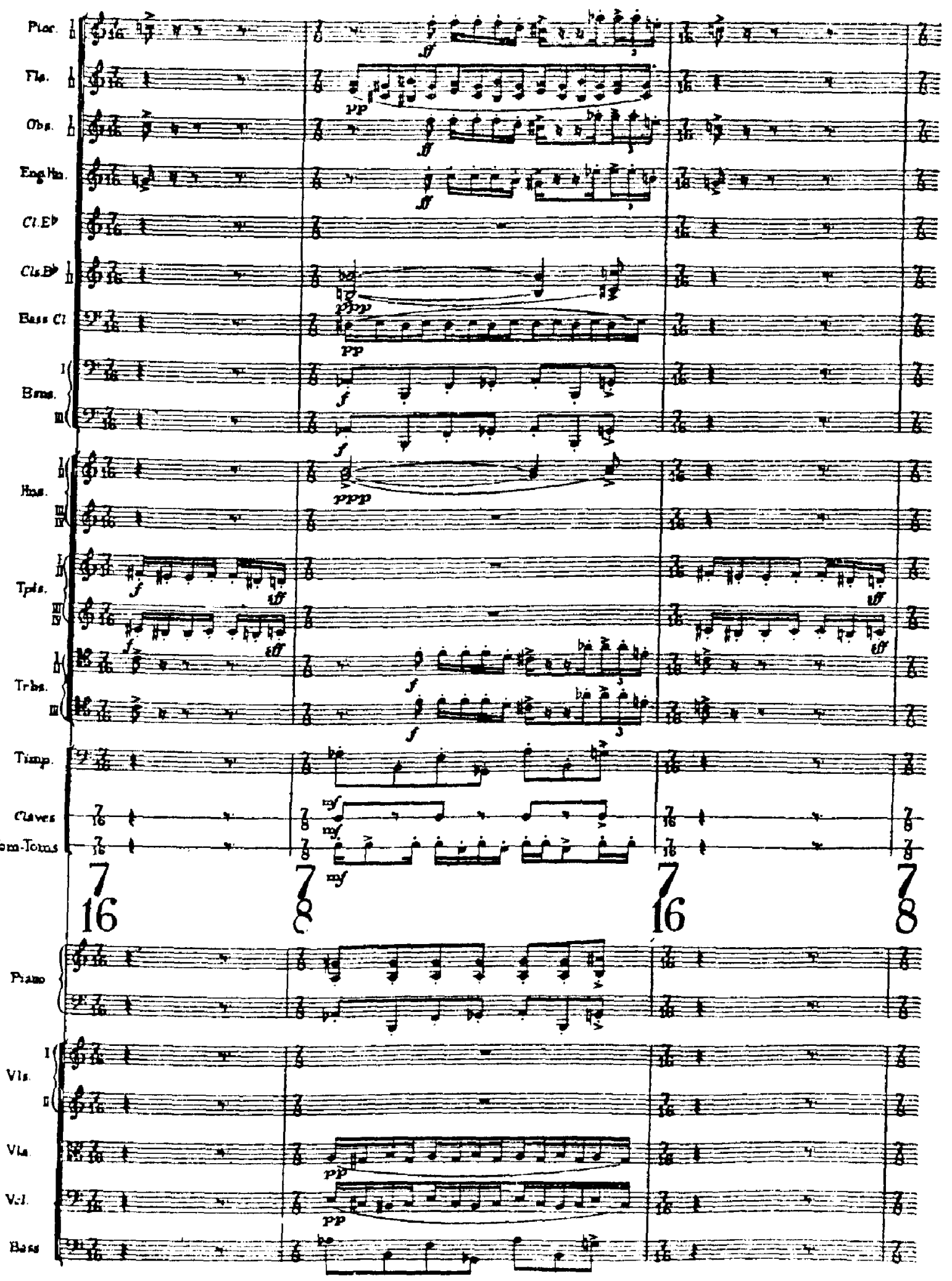

Figura 8 b 


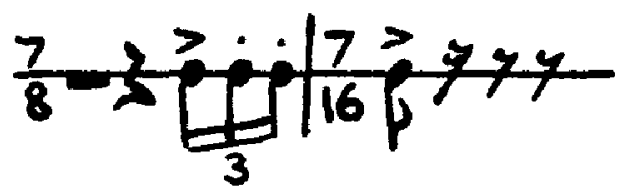

Figura 9

Silvestre Revueltas es uno de los más fascinantes, contradictorios e importantes personajes de la música mexicana.

Su desenfado, sus anhelos democráticos y libertarios, su lúcida y privilegiada inteligencia que la parte fuerte y clara de su emotividad (aquella que no estuvo en el alcoholismo, o tal vez aquella cuya delicada e intensa sensibilidad lo precipitó en él) equilibraba hasta los terrenos del cinismo, permitieron un efecto relajante de singular acción en el medio musical profesional de México. La contrapartida a la intensa seriedad de Chávez fue la válvula de escape, el desahogo social y profesional de Revueltas. El hombre del barril, el cínico capaz de cambiar un favor del amo del mundo por un instante de indiferente satisfacción. Una suave sonrisa, tan alejada de la mueca burlona como de la indiferente amargura, un suspiro de alivio, un silbido humorístico y despreocupado es la respuesta de Revueltas a la solemnidad de Carrillo, a la profunda convicción de Chávez, a la decente bondad de Ponce. Así, Revueltas resulta el más vivo, el más humano y a la vez el más mexicano de los compositores. Aquél tan sabio y tan viejo que ya puede reír sin mofa de los afanes humanos encadenados a un momento económico y social. Tal vez su música y actitud profesional eran su propia respuesta equilibrante a su politización y a su pasión democrática ¿quién puede afirmar con certeza las causas y razones de la conducta humana?

En un país con tantas carencias artísticas y culturales y con tan pocos héroes de sólido peso y valor que puedan trascender las fronteras de la vida física y la camarilla, Revueltas se manifiesta como un coloso. Como un hombre capaz de manejar un lenguaje universal y capaz de componer obras que tienen significadó e interés aun para los ajenos a la cultura nacional. Su obra marcó la cultura y la música mexicanas y la influencia de su pensamiento musical fue la contrapartida, el factor de equilibrio emocional que la trascendente y seria obra de Chávez reclamaba.

Además de los evidentes factores técnicos que pueden surgir del análisis de sus composiciones, hay en Revueltas esa extraña aura mística que se anuncia, en muchos casos injustificada, y que permite a doctos y legos intuir la presencia del genio. 
39

Ror b

F. 640

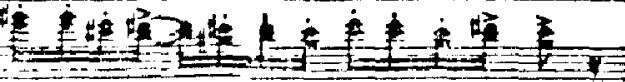

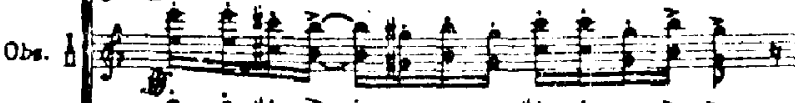

-

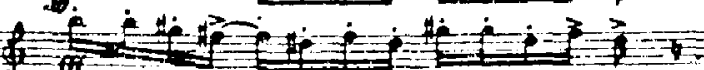

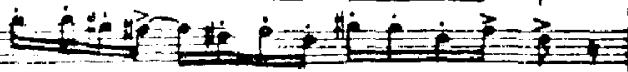

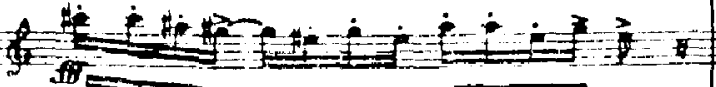

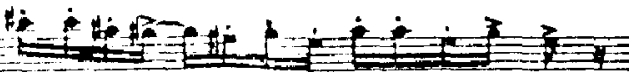

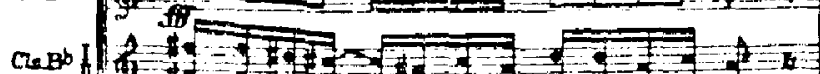

Burich. 1

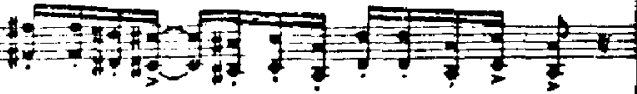

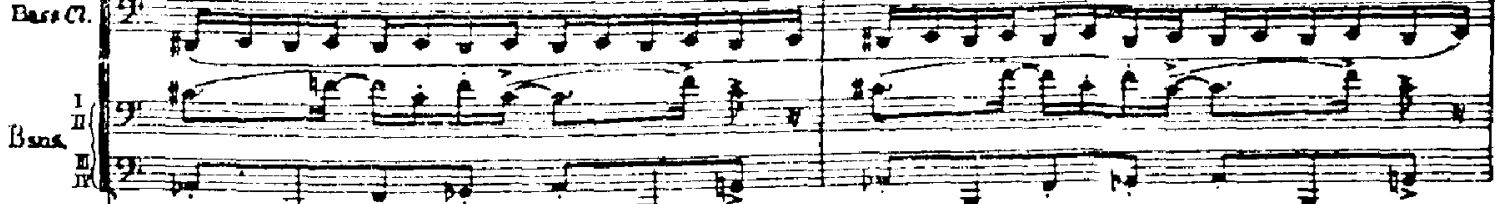

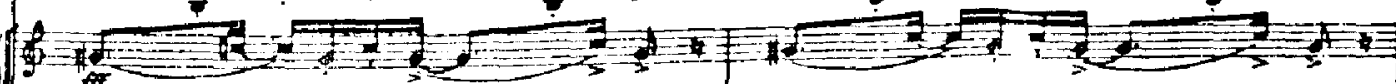

thes.

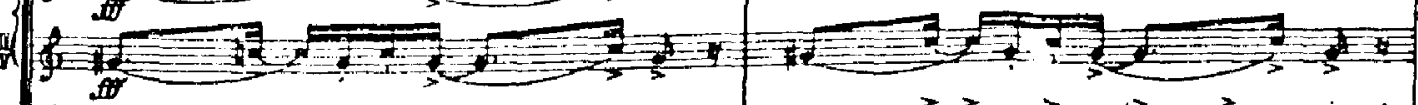

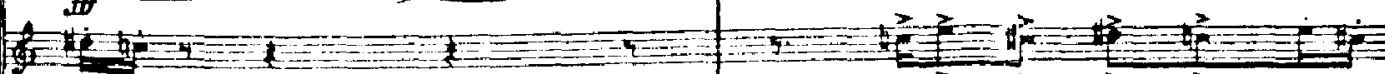

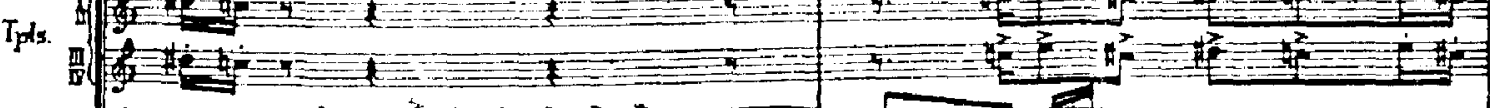

Trb.

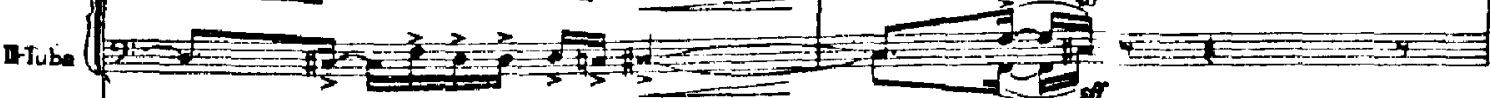

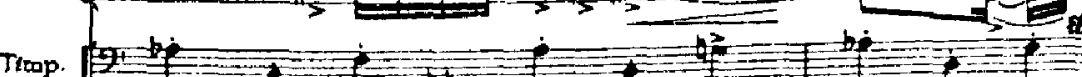

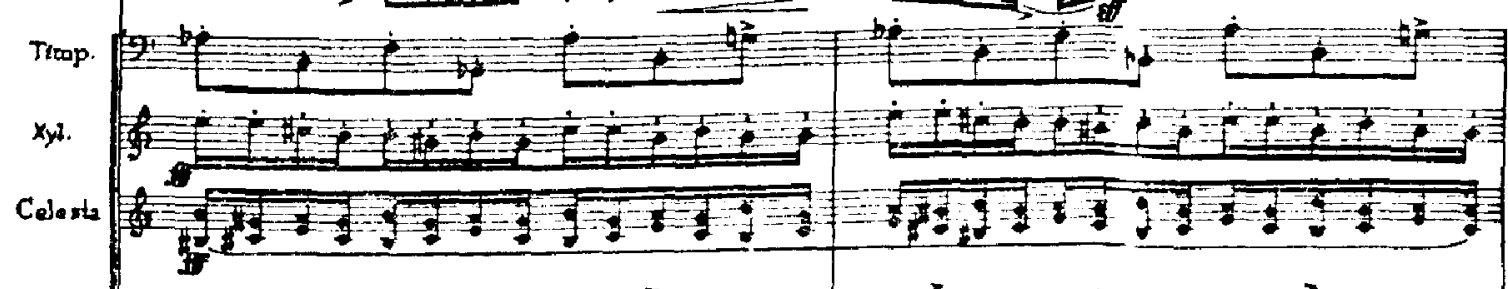

Gourd

Tom-Tam

1 $=3=3=$

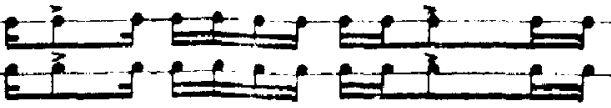

(3I)

39

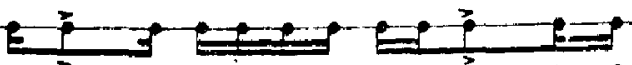

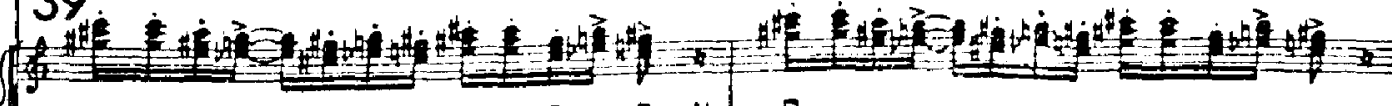

vis.

II

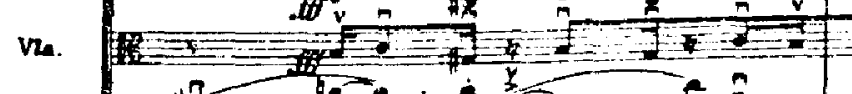

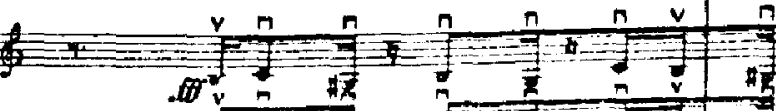

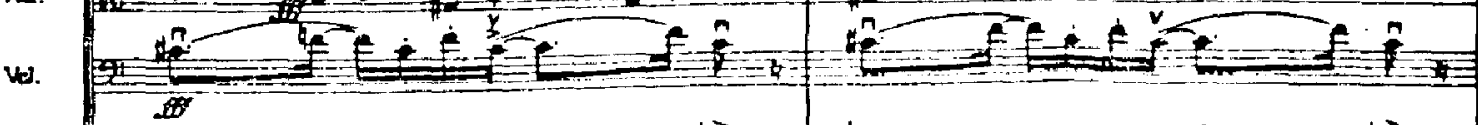

Boss 
Sin la obra de Carlos Chávez la música mexicana carecería de solidez. Sin la obra de Silvestre Revueltas nos veríamos privados del fresco empuje de la espontaneidad y la sinceridad de un hombre que pudo expresar lo mejor de sí a través del arte. 


\section{APÊNDICE}

\section{APUNTES BIOGRAFICOS}

Naci en Santiago Papasquiaro del Estado de Durango, el 31 de diciembre de 1899.

Creo que es un lugar cercano a las montańas, pues el recuerdo más lejano y vivo de mi infancia me ilumina un viaje por la sierra, amarrado a una mula -era muy pequeño- durmiendo el sueño bajo tiendas de campaña y sobre el suelo, cazando pajarillos con rifle de salón, recogiendo frutas en la madrugada, oyendo los lobos en la noche. Desde entonces me quedó un automático, tendido amor por los pinos, las montañas y los horizontes; así como más tarde, viviendo en Ocotlán del Estado de Jalisco, soñé con puertos y barcos - Ocotlín está a la orilla del río Lerma que desemboca en el Lago de Chapala- y me enamoré del mar soñado, para siempre. Fueron mis primeros amores: el cielo, el agua y la montaña. Después vino la música ... Más tarde la música por dentro.

Mi madre nació en un mineral del Estado de Durango llamado San Andrés de la Sierra, y alli vivió toda su juventud: hija de mineros y entre mineros. Entre quebradas y cascadas; y árboles y flores. Ella me ha contado su infinita curiosidad por saber del mundo que ocultaban las altas montañas que rodeaban su pueblo, sus sueños, y su siempre nueva admiración y amor por la naturaleza. Soñaba con tener algún día un hijo artista, poeta, escritor, músico, alguien que pudiera expresar todo lo que ella admiraba y amaba de la naturaleza y de la vida; a ello se debió probablemente que yo naciera con una malhadada afición por la música y por la pereza, y una inacabable nostalgia de nuevos horizontes. Era muy pequeño, tres años - me cuenta ella-, cuando por primera vez of la música. Era una orquestita de pueblo que tocaba la serenata en la plaza. Yo estuve de pie escuchando largo tiempo, y seguramente con una atención desmedida, pues me quedé bizco. $\mathrm{Y}$ bizco estuve por tres o cuatro dias (ahora, idesgracia mía!, ya no me quedo bizco ante los músicos). De niño (¿también de hombre?) preferí siempre dar tamborazos en una tina de baño y soñar cuentos, que hacer algo útil, y aś pasaba los días imitando con la voz diversos instrumentos, improvisando orquestas y canciones y acompañándome con la tina de baño. Esas redondas tinas de baño que siempre me gustaron más para tamboras que para baño. 
$\mathrm{Y}$ seguí soñando con música y paises remotos. Recuerdo dolorosamente el solfeo. A veces las desafinaciones me costaron coscorrones poco musicales. Mis lágrimas calleron sobre el "Eslava". Leí libros de viaje con lágrimas y "do, mi, do, mi, sol". Tenía seis años. Quería ser misionero en remotos lugares, predicador y músico. Me gustaron las vidas de los santos y de los bandidos.

Hay un barrio de Santiago que se llama España; creo que se cruza un arroyo para ir -tenía apenas ocho años cuando salí de Santiago, casi no lo recuerdo. Yo vivía un sueño de aventura cada vez que iba a España. Me mandaban allá con mi abuela cada vez que me daban aceite de ricino para que reposara la purga. Alli me ponía a limpiar frijoles y a tocar una flauta de carrizo.

Después toqué el violin. Lo empecé a estudiar allá por Colima, por Ocotlán, por Guadalajara. Mi pobre padre que era un poeta de su vida humilde nos llevaba de un lado para otro, porque sus negocios comerciales andaban de capa caída (era un comerciante que amaba el arte y la poesía. A él le debo lo mejor de mi vida interior y mi mejor amor para los hombres). Hice progresos rápidos y tocaba piezas y canciones populares o las improvisaba. Hice mi primera aparición en público, cuando tenía once años, en el Teatro Degollado de Guadalajara. Al día siguiente mi padre compró todos los perióclicos (descle entonces me han perseguido y ahora ya no los quiero comprar). Para él era una recompensa dulce por el gasto que habia hecho comprándome un traje nuevo para aquella ocasión ... ¡Estábamos tan "brujas"!

Mi padre, que tenía un vago temor de que la música no me diera para comer, me hizo estudiar teneduría de libros, taquigrafía, aritmética y ciencias ocultas, sin ningún resultado. Fui dependiente de una tienda de ropa y de abarrotes, con gran desesperación de los patrones, que siempre me mandaron a... tocar el violín. En revancha creo haberme robado uno que otro quinto para comprar "leche quemada" y pasteles, que eran mi debilidad. Cada domingo me daban un tostón del que gastaba veinticinco centavos en pasteles y el resto se lo daba a mi abuela con quien vivía pobremente en un cuarto redondo.

Fui creciendo y tocando.

Vine a México ¡México! Hice versos inevitables y escribi cartas con puros puntos suspensivos. $\mathrm{Mi}$ buen padre se alarmaba...

Seguí estudiando música y fui poco aplicado. Desde muy temprano amé a Bach y a Beethoven. Me gustaba pasearme a grandes zancadas con la melena alborotada y los brazos cruzados a la espalda, por las 
románticas avenidas de Chapultepec. Siempre tuvieron gran influjo sobre mí esas litografías y grabaclos que muestran al pobre de Beethoven con cara de pocos amigos desafiando un desatado tormentón. Yo no podía hacer menos.

He tenido muchos maestros. Los mejores no tenian títulos y sabian más que los otros. De allí que siempre haya tenido muy poca veneración por los títulos. Ahora, después de muchos años sigo estudiando, sigo teniendo maestros, escribo música, sueño con remotos paises, y a veces doy tamborazos en tinas de baño.

\section{Silvestre Revueltas}

México, 13 de marzo de 1938

Estas noticias biográficas fueron publicadas por José Revueltas en Apuntes para nua semblanza de Silvestre, p. 66, México, 1966. 


\section{BIBLIOGRAFIA}

Anónimo. "Nuestras entrevistas con Silvestre Revueltas", en Cultura Musical, núm. 1, México, nov. de 1936, p. 8.

Castañeda, Daniel. "La Música y la Revolución Mexicana", en Boletin Latino. americano de Música, vol. v, Montevideo, octubre de 1941, p. 437.

Chase, Gilbert. A Guide to the Music of Latin America, Biblioteca del Congreso y Unión Panamericana, Washington, 1962.

Contreras, Guillermo. Silvestre Rezueltas: genio atormentado, México, 1954.

Galindo, Blas. "El Nacionalismo Musical Mexicano", en Boletin del Departamento de Música de la Secretaría de Educación Pública, núm. 1, México, 1946, p. 3.

Gutiérrez Heras, Joaquín. Notas, a los programas de la OFUNAM, México, 1975.

Mancisidor, José. "Perfil de Silvestre Revueltas", en Ruta, núm. 15, vol. vir, México, 1938.

Marinello, Juan. Imagen de Silvestre Revueltas, La Habana, 1966.

Mayer-Serra, Otto. Panorama de la música mexicana desde la Independencia hasta la actualidad, México, 1941.

Mayer-Serra, Otto. "Silvestre Revueltas and musical nationalism in Mexico", en Musical Quarterly, vol. xxxII, núm. 2, New York, 1941.

Muñoz, Peggy. "Silvestre Revueltas", en Musical América, New York, febrero de 1958.

Revueitas, José. Apuntes para una semblanza de Silvestre, México, 1966.

Revueltas, Silvestre. "Contracanto", en El Universal, México, D. F., 8 de noviembre de 1933.

Revueltas, Silvestre. Epistolario, México, 1976.

Revueltas, Silvestre. Algunas cartas intimas, notas y escritos (apéndice del libro de José Revueltas), México, 1966.

Stevenson, Robert. Music in Mexico, New York, 1971.

\section{DISCOGRAFIA}

Allegro, para piano, Somer; Desto 6426.

Caminos, Mata, New Philharmonia; RCA, MRSA-1.

Cuauhnáhuac, Mata, New Philharmonia; RCA, MRSA-1.

Danza Geométrica, Mata, New Philharmonia; RCA, MRSA-1.

Dos piececitas serias, Quinteto Westwood; Cristal S-812.

Homenaje a Garcia Lorca, Mata, New Philharmonia; RCA, MRSA-1.

Itinerarios, Mata, New Philharmonia; RCA, MRSA-1.

Janitzio, Mata, New Philharmonia; RCA, MRSA-1.

Redes, Herrera de la Fuente, Orquesta Sinfónica Nacional; Musart, MCD 3017;

Mata, Filarmónica de la UNAM; Voz Viva de México, VVMN.7; New Philhar-

monia; RCA, MRSA-1; Mester, Orquesta de Louisville; Lou S-696.

Sensemayá, Bernstein, Filarmónica de New York; Columbia, MS-6514; Herrera de la Fuente, Orquesta Sinfónica Nacional; Musart, MCD 8017; Mata. New Philharmonia; RCA, MRSA-1.

Ventanas, Whitney, Orquesta de Louisville; Lou S-672. 


\section{PRINCIPALES OBRAS DE REVUELTAS}

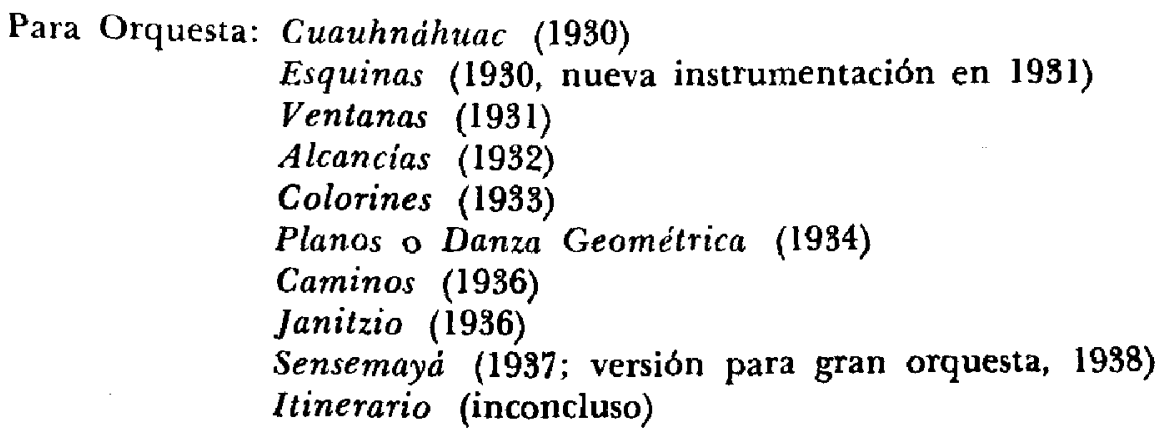

Música de Cámara: Tres Cuartetos de Cuerdas (1930-1931)

Dúo para pato y canario (1931), voz y pequeña orquesta

Ranas (1931), voz y piano

El Tecolote (1931), voz y piano

Tres piezas (1932), violín y piano

Feria (1932), cuarteto de cuerdas

Toccata (1933), violin y pequeña orquesta

Ocho por radio (1983), octeto

Allegro (1935), piano

Homenaje a Federico Garcia Lorca (1936), pequeña orquesta

El renacuajo paseador (1936), pequeña orquesta

Dos canciones (1938), voz y diversos instrumentos (texto de Nicolás Guillén)

Siete canciones (1938), voz y piano (texto de García Lorca)

La Coronela (1940), ballet inconcluso, terminado por Blas Galindo e instrumentado por Candelario Huízar.

\section{MÚSICA PARA PELICULAS}

Redes (1935)

Vảmonos can Pancho Villa (1936)

El Indio (1938)

Ferrocarriles de Baja California (1938)

La Noche de los Mayas (1939), versión de concierto con el título de Música para charlar

Bajo el Signo de la Muerte (1939)

Los de Abajo (1940) 